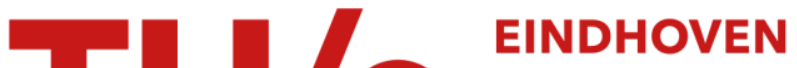 UNIVERSITY OF TECHNOLOGY
}

\section{Lattice deformation in InAs/GaAs superlattices characterized by MeV ion channeling}

\section{Citation for published version (APA):}

Selen, L. J. M., IJzendoorn, van, L. J., Janssen, F. J. J., Voigt, de, M. J. A., \& Smulders, P. J. M. (2001). Lattice deformation in InAs/GaAs superlattices characterized by MeV ion channeling. Physical Review B, 64(24), 245319-1/6. [245319]. https://doi.org/10.1103/PhysRevB.64.245319

DOI:

10.1103/PhysRevB.64.245319

Document status and date:

Published: 01/01/2001

\section{Document Version:}

Publisher's PDF, also known as Version of Record (includes final page, issue and volume numbers)

\section{Please check the document version of this publication:}

- A submitted manuscript is the version of the article upon submission and before peer-review. There can be important differences between the submitted version and the official published version of record. People interested in the research are advised to contact the author for the final version of the publication, or visit the $\mathrm{DOI}$ to the publisher's website.

- The final author version and the galley proof are versions of the publication after peer review.

- The final published version features the final layout of the paper including the volume, issue and page numbers.

Link to publication

\section{General rights}

Copyright and moral rights for the publications made accessible in the public portal are retained by the authors and/or other copyright owners and it is a condition of accessing publications that users recognise and abide by the legal requirements associated with these rights.

- Users may download and print one copy of any publication from the public portal for the purpose of private study or research.

- You may not further distribute the material or use it for any profit-making activity or commercial gain

- You may freely distribute the URL identifying the publication in the public portal.

If the publication is distributed under the terms of Article 25fa of the Dutch Copyright Act, indicated by the "Taverne" license above, please follow below link for the End User Agreement:

www.tue.nl/taverne

Take down policy

If you believe that this document breaches copyright please contact us at:

openaccess@tue.nl

providing details and we will investigate your claim. 


\title{
Lattice deformation in InAs/GaAs superlattices characterized by MeV ion channeling
}

\author{
L. J. M. Selen, L. J. van IJzendoorn,* F. J. J. Janssen, and M. J. A. de Voigt \\ Research Institutes CPS and COBRA, Cyclotron Laboratory, Department of Applied Physics, Eindhoven University of Technology, P.O. \\ Box 513, 5600 MB Eindhoven, The Netherlands \\ P. J. M. Smulders \\ Materials Science Center, University of Groningen, Groningen, The Netherlands
}

(Received 28 May 2001; published 4 December 2001)

\begin{abstract}
Axial and planar $\mathrm{MeV}$ ion-channeling experiments are performed on a InAs/GaAs superlattice with ten coherent buried InAs nanofilms in GaAs. We have measured a step in the channeled Rutherford backscattering spectra, which depends on the incidence angle of the ions. With Monte Carlo simulations, the average tetragonal distortion in the nanofilms can be determined from the axial channeling measurements, although the separate contributions of each individual nanofilm cannot be resolved in the measured spectra. Planar channeling measurements show a higher step, but a detailed resemblance between measurements and simulations cannot be achieved.
\end{abstract}

DOI: $10.1103 /$ PhysRevB.64.245319

PACS number(s): 61.85.+p, 68.55.-a, 02.70.Uu

\section{INTRODUCTION}

In modern semiconductor technology, the application of buried single-crystalline meta-stable strained films with a thickness in the nanometer range is increasing. Examples are semiconductor devices such as solid-state lasers, heterojunction bipolar transistors, and tunnel junctions. Characterization of these strained layers is important, since the lattice deformation in strained films is an important factor determining the materials and device properties.

The presence of such a strained nanofilm leads to a step in the yield of the host crystal in a channeled Rutherford backscattering (RBS) spectrum. In previous work we showed that the step height as a function of incident beam direction combined with Monte Carlo simulations provides useful information on the tetragonal distortion in the buried nanofilm. ${ }^{1-3}$

In this work we extend this method to more complex samples. For that purpose we performed [011] axial and $\{011\}$ planar channeling measurements on an InAs/GaAs superlattice structure of ten buried InAs nanofilms in GaAs. In the past Picraux et al. used planar channeling to investigate strain in superlattices under conditions of catastrophic dechanneling. ${ }^{4,5}$ Their method is extremely sensitive to the relative strain between the superlattice layers, but is limited to superlattices with layers of equal thickness. The method presented in this paper does not have that limitation.

\section{EXPERIMENT}

The InAs/GaAs samples were grown in a Varian GenII molecular beam epitaxy system at Eindhoven University of Technology. First a 675-nm-thick GaAs buffer layer is grown on a [001]-oriented GaAs substrate. On top of this a 0.36nm-thick InAs layer, i.e., 1.1 monolayer (ML) InAs, and a $18.08 \mathrm{~nm}$ thick GaAs barrier layer were grown pseudomorphically, both at $410^{\circ} \mathrm{C}$. This combination of an InAs and GaAs layer is repeated 8 times; subsequently another InAs layer of $0.36 \mathrm{~nm}$ is grown. This superlattice structure is capped with $97.9 \mathrm{~nm} \mathrm{GaAs}$ at $650^{\circ} \mathrm{C}$, a 30.0-nm-thick
$\mathrm{Al}_{0.33} \mathrm{Ga}_{0.67} \mathrm{As}$ layer, and a 17.0 -nm-thick GaAs layer, both grown at $700^{\circ} \mathrm{C}$. The thickness of the ultrathin InAs layers was determined with an accuracy better than $0.1 \mathrm{ML}$, i.e., $0.03 \mathrm{~nm}$, with high-resolution double-crystal $\mathrm{x}$-raydiffraction measurements at the Eindhoven University of Technology. ${ }^{6}$ The thickness of the capping layer was determined with an accuracy of $5 \mathrm{~nm}$, and the thickness of the barrier layers is accurate within $2 \mathrm{~nm}$. Furthermore, the $\mathrm{x}$-ray measurements provide evidence that the lattice mismatch is fully accommodated by an elastic distortion of the InAs unit cell; i.e., the InAs layer is grown pseudomorphically. ${ }^{6}$ Figure 1 shows a schematic drawing of the sample.

The tetragonal distortion is a quantity for the strain defined as $\varepsilon_{T}=\varepsilon_{\perp}-\varepsilon_{\|}=\left(a_{\perp}-a_{\|}\right) / a_{V}$, where $a_{\perp}$ is the perpendicular lattice constant, $a_{\|}$the in-plane lattice constant, and $a_{V}$ the Vegard crystal lattice constant, which according to Vegard's law is a linear combination of the lattice constants of the components weighted with their concentration. The in-plane strain $\varepsilon_{\|}$and the perpendicular strain $\varepsilon_{\perp}$ are defined

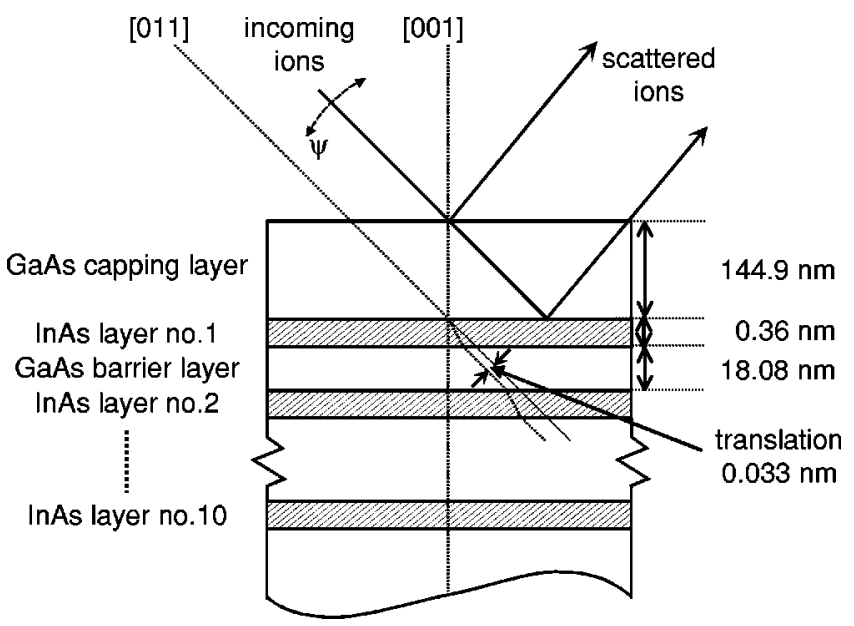

FIG. 1. Schematic drawing of the sample. The directions of the [001] surface normal, the [011] axis, the incoming ion beam, and the tilt angle of the ion beam are indicated. 

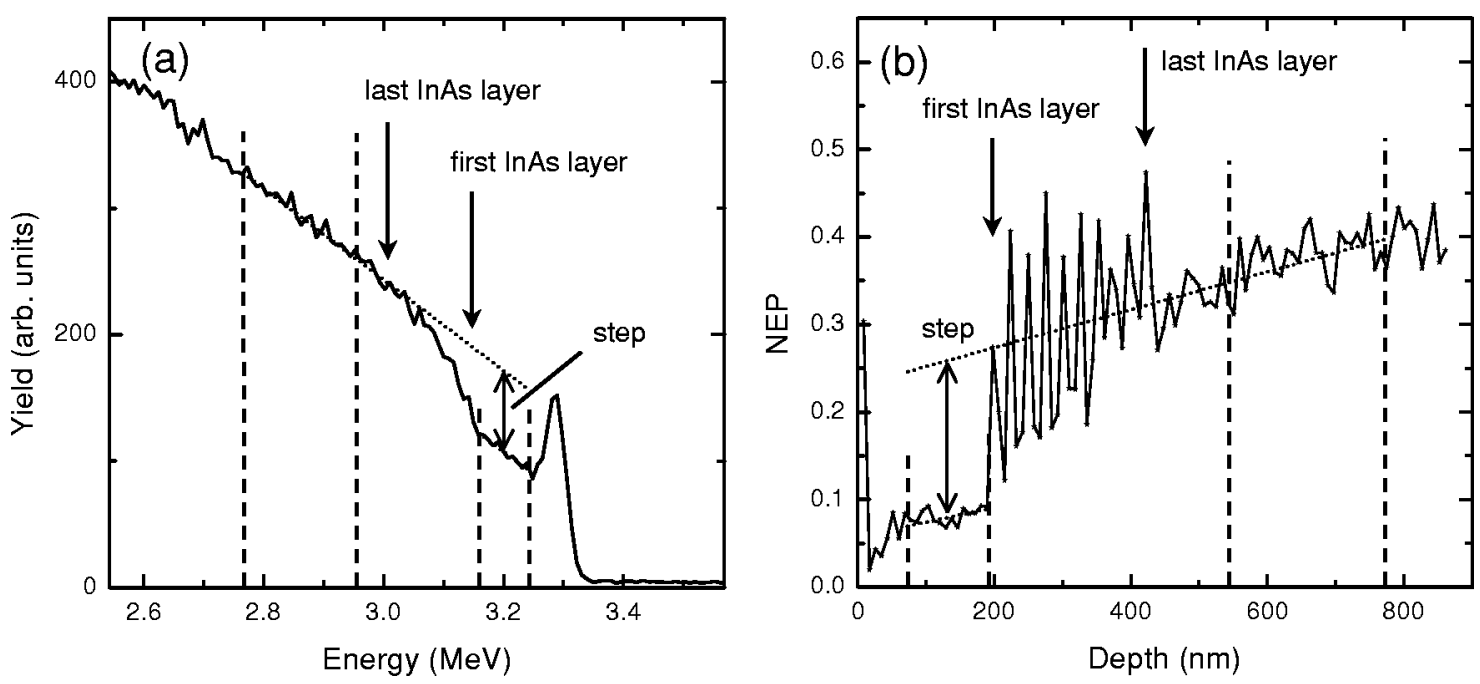

FIG. 2. Measured RBS spectrum (a) and calculated NEP spectrum (b) of a measurement corresponding to the sample tilted $0.20^{\circ}$ away from the [011] axis into the $\{001\}$ plane using $3.5 \mathrm{MeV} \mathrm{He}^{+}$ions. The energy of the ions scattered at the first and last InAs layer is indicated.

as the relative deviations of the lattice constants from the Vegard crystal lattice constant. Assuming the absence of dislocations, the tetragonal distortion in each InAs film is $\varepsilon_{T}$ $=0.14$. For a thickness of $1.1 \mathrm{ML}$, this leads to a translation of $0.033 \mathrm{~nm}$ of the GaAs $\langle 011\rangle$ strings and $\{011\}$ planes traversing each InAs layer (see Fig. 1). The rotation angle at the interfaces is $3.98^{\circ}$, which is about 8 times larger than the critical angle for channeling in our experiments (typically $\left.0.5^{\circ}\right)$.

The incoming ion beam is aligned with the [011] axis of the capping layer for axial channeling experiments. For planar channeling experiments, the beam is tilted $5^{\circ}$ away from the [011] axis into the $\{011\}$ plane, which is the plane through the [011] axis perpendicular to the plane of sight in Fig. 1. To obtain an angular scan, the ion beam is tilted along the angle $\psi$ between the ion beam and the [011] axes or $\{011\}$ planes as indicated in Fig. 1. Every incorporated InAs layer is in fact a tetragonally deformed nanofilm, which is expected to induce an increase of the scattering yield in a channeled spectrum for off-normal axes or planes. ${ }^{1-3}$

Ion-channeling experiments have been performed with 2-6 $\mathrm{MeV} \mathrm{He}^{+}$ion beams from the 2-30 MeV Philips AVF Cyclotron at Eindhoven University of Technology. In order to compare the scattering yield in the experiments quantitatively, a rotating vane with a 88 -nm-thick gold film is placed in the ion beam. The yield of $\mathrm{He}^{+}$ions scattered from the gold film is measured with a $25 \mathrm{~mm}^{2}$ Canberra Passivated Implanted Planar Silicon (PIPS) detector. The samples were placed in a three-axis goniometer with an angular resolution $<0.005^{\circ}{ }^{7}$ With two sets of slits the beam divergence was limited to $0.07^{\circ}$ full width at half maximum (FWHM). Backscattered ions were detected with a $100 \mathrm{~mm}^{2}$ Canberra PIPS detector with a total energy resolution of approximately 20 $\mathrm{keV}$, positioned at a backscattering angle of $130^{\circ}$.

A study with Monte Carlo (MC) simulations is required to relate the observed step height curves to the tetragonal distortion in the InAs layers. For that purpose the MC channeling simulation program FLUX7 is used, which is an improved and extended version of FLUX. ${ }^{8}$ The calculations are based on binary collisions of the incoming ion and the target nuclei. In addition, the effect of distant rows of target atoms is accounted for by a continuum string potential. Furthermore, the thermal vibrations of the target atoms and the stopping of the projectiles by electrons in the solid are incorporated.

Although simulations of planar channeling measurements on buried $\mathrm{Si}_{1-x} \mathrm{Ge}_{x}$ nanofilms in a $\mathrm{Si}$ host lattice have been proven to be quite sensitive to the ion-atom potential, ${ }^{2,3}$ the choice of ion-atom potential in simulations of planar channeling in a system with a GaAs host lattice is of negligible influence. The well-known universal potential of Ziegler, Biersack, and Littmark $^{9}$ is used for simulations on our sample. The $\mathrm{Al}_{0.33} \mathrm{Ga}_{0.67} \mathrm{As}$ in the capping layer is substituted by GaAs in the simulations, which is of negligible influence on the channeling simulations. The strain in each InAs layer leads to a kink of $3.98^{\circ}$ in the [011] axes and $\{011\}$ planes at the GaAs/InAs interfaces, which can be simulated by rotating the velocity vector of the ions at the beginning and end of each InAs layer. One of the output parameters of FLUX7 is the nuclear encounter probability (NEP) with a target atom to cause an event such as large-angle scattering (in RBS), a high-energy recoil of the target atom, or a nuclear reaction. The NEP is normalized by the probability for a random medium with the same density of atoms, ${ }^{8}$ and the FLUX7 simulation code is used to perform MC calculations of the NEP as a function of the depth for the InAs/GaAs sample.

\section{AXIAL CHANNELING MEASUREMENTS}

Figure 2(a) shows a typical axially channeled RBS spectrum of the InAs/GaAs sample with a step in the yield in the depth interval of the superlattice, measured with the detector at a forward scattering angle of $65^{\circ}$. The spectrum is one of the spectra obtained in an angular scan through the [011] axis. In the spectrum the total step height corresponds to the summed effect of contributions from the ten separate InAs layers. The step height is taken to be the difference between the average yield in the depth intervals of 380-550 and 60$140 \mathrm{~nm}$ [indicated by the dashed lines in Fig. 2(a)]. To cor- 


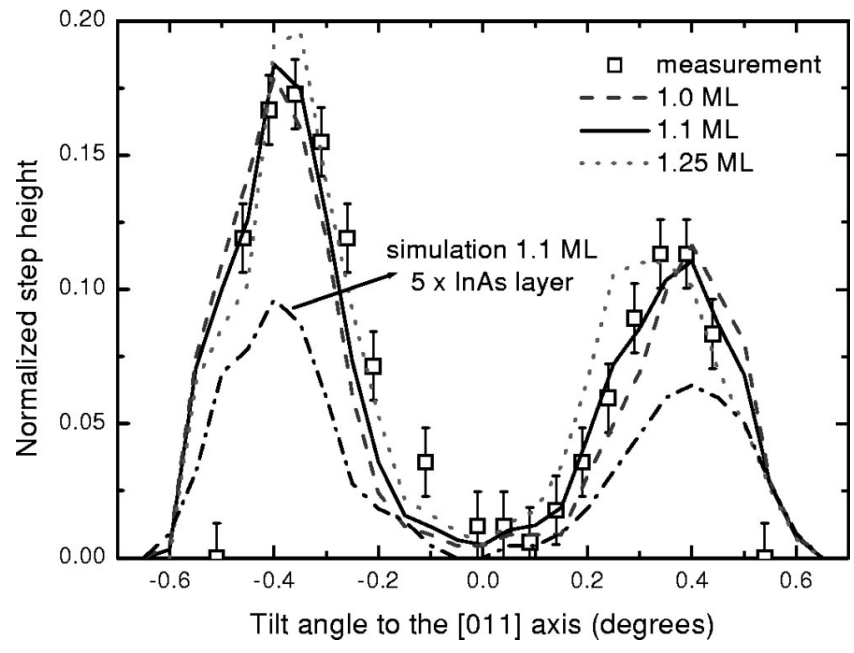

FIG. 3. Measured (squares) and calculated (lines) [011] axial step height curves for $3.5 \mathrm{MeV} \mathrm{He}^{+}$ions. Calculations were done assuming InAs layers with a thickness of 1.0 (dashed line), 1.1 (solid line), and 1.25 ML (dotted line). Furthermore, the calculated step height curve for a sample with five InAs layers is shown. The step heights are normalized to the yield for a nonchanneling direction.

rect for the angular-dependent dechanneling rate, the average yield in the interval behind the superlattice structure is linearly extrapolated to the interval before the superlattice structure, and the slope of the extrapolation corresponds to the increase in dechanneling [see Fig. 2(a)].

Due to the small difference between the kinematic factors of the interaction of $\mathrm{He}^{+}$ions with $\mathrm{Ga}$ and $\mathrm{As}$ and a detector resolution of $20 \mathrm{keV}$, only one surface peak can be distinguished in the energy spectrum. Since the stopping power of channeled 3.5 $\mathrm{MeV} \mathrm{He}^{+}$ions in GaAs is approximately 1.0 $\mathrm{keV} / \mathrm{nm},{ }^{9}$ the depth resolution for this measurement configuration is about $20 \mathrm{~nm}$. Due to this depth resolution, energy straggling effects, and the small difference in the kinematic factors of $\mathrm{Ga}$ and As, the individual step heights in the spectra resulting from each InAs layer cannot be distinguished in Fig. 2(a). Therefore, the tetragonal distortion of the individual layers was not measured separately, and the obtained characteristics involve the summed effect of all InAs layers.

In Fig. 2(b) a plot of the NEP as a function of the depth is shown for a FLUX7 simulation of the InAs/GaAs sample. The depth steps in the calculations are chosen small enough to distinguish the increase in scattering yield resulting from the ten individual InAs layers in the NEP spectrum. The extrapolated difference between the average NEP in the depth intervals of 84-200 and 545-782 $\mathrm{nm}$ measured along the [011] direction is taken as the calculated step height [see Fig. 2(b)].

The step height in the yield depends on the angle $\psi$ between the crystal axis and the ion beam. In Fig. 3 the step height from the experiments and calculations is plotted as a function of the angle $\psi$. Two maxima appear and in combination with $\mathrm{MC}$ calculations the angular separation between the maxima can be related to the translation of the [011] axes across the strained nanofilm. The tetragonal distortion in the nanofilm can be retrieved, when the thickness of the nanofilm is known. ${ }^{1}$ Simulations were performed with three dif- ferent translations of the atomic [011] strings corresponding to fully deformed InAs layers with a thickness of 1.0, 1.1, and 1.25 ML, corresponding to a translation across each InAs layer of $0.030,0.033$, and $0.037 \mathrm{~nm}$, respectively. The simulations with a translation corresponding to 1.1-ML-thick InAs layers show the best resemblance to the measurements.

It has been investigated whether the angular dependence of the step height curves of Fig. 3 is determined by the separate contributions due to the translation at each InAs layer or by a collective effect of the total superlattice structure. Simulations are performed on an equivalent InAs/GaAs sample containing five InAs layers instead of ten, and the results are added to Fig. 3. Clearly, the angular dependence of the step height curve is the same for both samples, and furthermore, the step height curve for the sample with five InAs layers is generally half the height of the curve for the sample with ten InAs films. This shows that the angular dependence of the step height curve is determined by the separate contributions from the individual InAs films. We can conclude that when the step height due to the presence of a single strained nanofilm in a sample is too small to determine a step height curve, a superlattice structure with multiple equal nanofilms can be grown from which the tetragonal distortion can still be determined for the separate nanofilms.

Note that in Fig. 3 the heights of the two maxima are not equal, which suggests that a steady-state flux distribution is not reached, when the channeled ions reach the superlattice structure. Channeled ions start with oscillating trajectories within a channel, and the coherency between the trajectories of different ions disappears typically within 100-200 nm due to energy straggling and interaction with target electrons. ${ }^{10}$ The capping layer of our sample is $145 \mathrm{~nm}$ thick. To investigate if the flux distribution is steady state at the superlattice, experiments and simulations have been performed with 2 and $6 \mathrm{MeV} \mathrm{He}^{+}$ions, since the oscillation wavelength of the ion trajectories depends on the energy of the incoming ions. To compare the step height curves for different energies, the tilt angles are scaled with the critical angles for channeling, which for the [011] axis of GaAs are $0.87^{\circ}, 0.66^{\circ}$, and $0.50^{\circ}$ with 2, 3.5, and $6 \mathrm{MeV} \mathrm{He}{ }^{+}$ions, respectively. The results are presented in Fig. 4, which shows that the step height curves for negative tilt angles are the same within the experimental error. For positive tilt angles, the maximum in the step height curves changes for different energies, which confirms that the flux distribution is not steady state at the superlattice.

From Fig. 3 it can be concluded that the translation of the [011] strings across the InAs layers can be determined with an accuracy of about $0.004 \mathrm{~nm}$, which is twice as good as that for experiments and simulations on a single nanofilm. ${ }^{1}$ Furthermore, the thickness of the InAs layers found with this method agrees very well with the thickness of 1.1 $\pm 0.1 \mathrm{ML}$, which was determined with high-resolution X-ray diffraction (see Sec. II).

\section{PLANAR CHANNELING MEASUREMENTS}

The sensitivity for measuring tetragonal deformation in nanofilms depends on the magnitude of the translation of the 


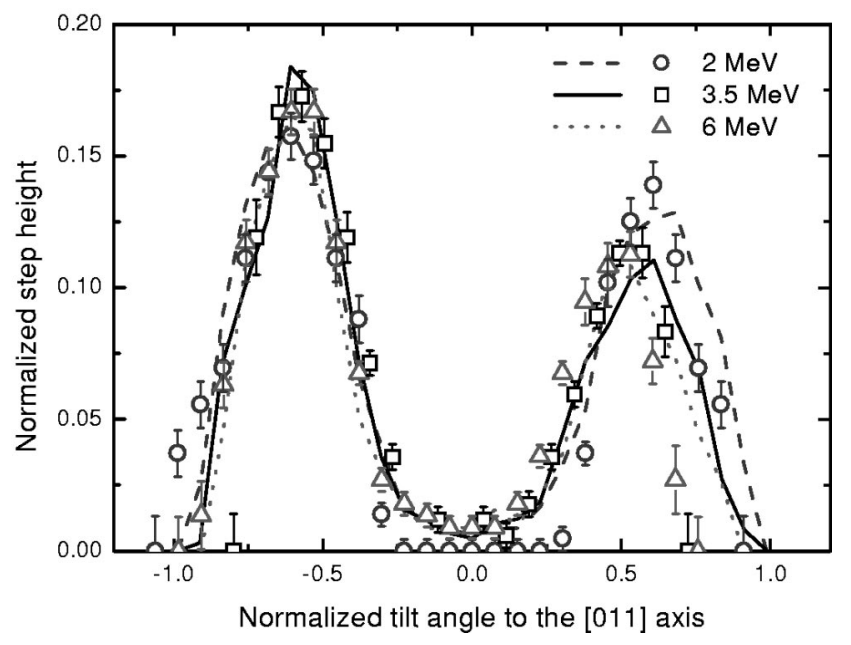

FIG. 4. Measured (symbols) and calculated (lines) [011] axial step height curves for $2,3.5$, and $6 \mathrm{MeV} \mathrm{He}^{+}$ions.

channeling axes or planes across the nanofilm. ${ }^{1-3}$ Planar channeling experiments show a more pronounced step in the channeled RBS spectrum, due to the relatively small distance between the $\{011\}$ planes compared to the distance between opposite rows in the [011] channels, which is 0.200 and $0.400 \mathrm{~nm}$, respectively, for a zinc-blende-type GaAs crystal. In previous work it was shown that for planar channeling, oscillations in the flux distribution are still present at a depth corresponding to the depth of the buried InAs films, ${ }^{2,3}$ and MC simulations are required to explain the step height curves. The wavelength of the oscillations in the flux distribution is energy dependent and determines the flux distribution after traversing the capping layer., ${ }^{2,3}$ Consequently, planar channeling experiments have been performed to investigate the energy dependence of the step height curves.

Figure 5 shows two measured planar channeled spectra of the InAs/GaAs sample with a step in the yield at the depth of the superlattice structure. In the spectra of Fig. 5 the total step height is clearly not equally distributed over the ten separate InAs layers. It is remarkable that the spectrum measured at $6 \mathrm{MeV}$ contains two steps, approximately at the energies corresponding to the first and last InAs film in the sample. The same effect is observed in the calculated NEP spectrum for $6 \mathrm{MeV} \mathrm{He}{ }^{+}$ions at the same tilt angle. Note that a double step is not observed in the measurements and simulations with $2 \mathrm{MeV} \mathrm{He}{ }^{+}$ions. Therefore, additional simulations with $6 \mathrm{MeV} \mathrm{He}^{+}$ions were performed on a sample with ten InAs layers with GaAs barrier layers of 15 and 22, instead of $18.08 \mathrm{~nm}$, which showed that the effect of two steps appearing in the spectrum is specific for $18.08 \mathrm{~nm}$. For $15 \mathrm{~nm}$ only one step occurs, and for $22 \mathrm{~nm}$ two steps appear, but the effect is less pronounced. Apparently, the combination of thickness of the barrier layers and the wavelength of the oscillating trajectories determines the appearance of two steps.

The measured and calculated step height curves of the single step with $2 \mathrm{MeV}$ and the two separate steps with 6 $\mathrm{MeV}$ are plotted in Fig. 6. For both the measurements and the simulations, the steps are determined from the difference in the extrapolated average yield in the depth intervals of $380-550$ and 60-140 nm for $2 \mathrm{MeV}$ and 380-550, 210310 , and $60-140 \mathrm{~nm}$ for $6 \mathrm{MeV}$ (see Fig. 5). For $6 \mathrm{MeV}$ the general shape of the simulated step height curves is in good agreement with the measurements, except for the negative step heights, which do not appear for the measurements. For $2 \mathrm{MeV}$ the agreement is worse.

In order to investigate the dependence of the shape of the planar step height curves on the thickness of the layers in the InAs/GaAs superlattice, additional planar channeling simulations are performed with a thickness of 1.0 and 1.25 ML for the InAs layers. The calculated step height curves are shown in Fig. 7 together with the measured curves. The differences in the calculated step height curves are small and the resemblance of all the calculated step height curves with the measurements is relatively good.

For planar channeling measurements on a single buried nanofilm, the shape of the step height curve is determined by
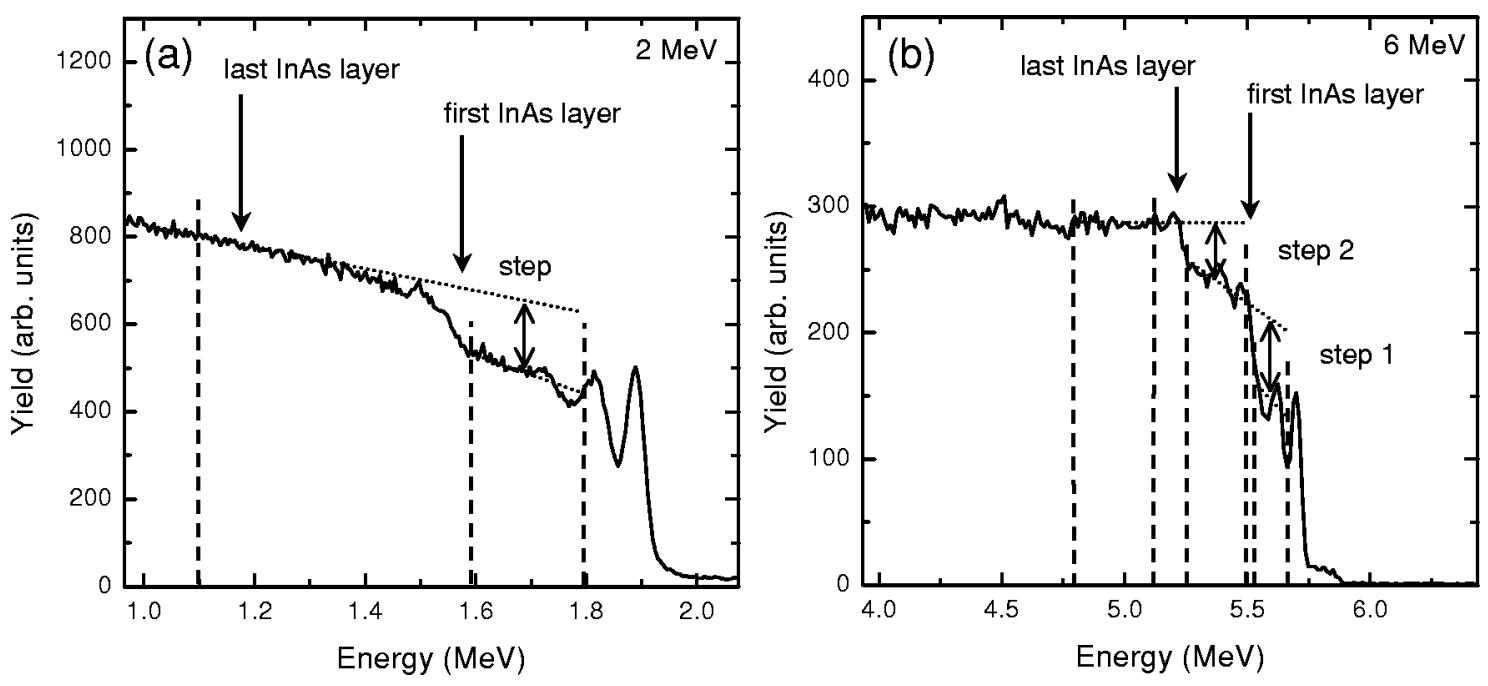

FIG. 5. Measured planar channeled RBS spectra for $2 \mathrm{MeV} \mathrm{He}^{+}$ions with the sample tilted $0.10^{\circ}$ to the $\{011\}$ plane (a) and $6 \mathrm{MeV}^{+}$ ions with the sample tilted $-0.02^{\circ}$ to the $\{011\}$ plane (b). 

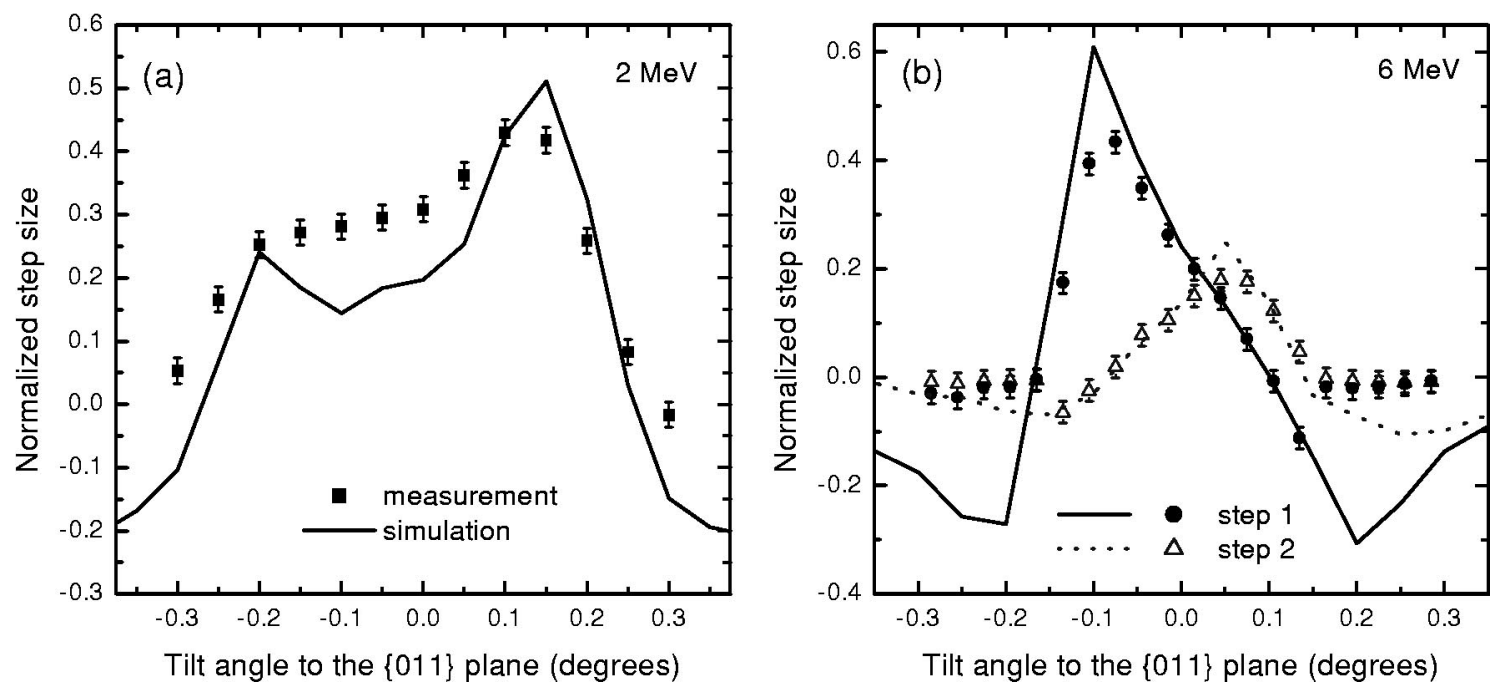

FIG. 6. Measured (symbols) and calculated (lines) $\{011\}$ planar step height curves for 2 (a) and 6 (b) $\mathrm{MeV} \mathrm{He}^{+}$ions.

the thickness of the capping layer, since this determines the phase of the oscillations. ${ }^{2,3}$ Oscillations in the channeled flux distribution are expected to be still present at the depth of the InAs/GaAs superlattice structure, and therefore, the thickness of the capping layer and barrier layers is expected to influence the measured step height curves. To investigate these presumptions, simulations are performed in which the thickness of the capping layer and the barrier layers is varied. The results are presented in Fig. 8 for simulations with $2 \mathrm{MeV}$ $\mathrm{He}^{+}$ions. Figure 8(a) indeed shows that the shape of the step height curve depends on the thickness of the capping layer; however, the differences between the simulated step height curves are small compared to the differences with the measured step height curve. Also variations in the thickness of the barrier layers result in only small differences in the step height curves compared to the difference with the measurements; see Fig. 8(b). Simulations with $6 \mathrm{MeV} \mathrm{He}^{+}$ions are not presented here, but exactly the same conclusions can be drawn.

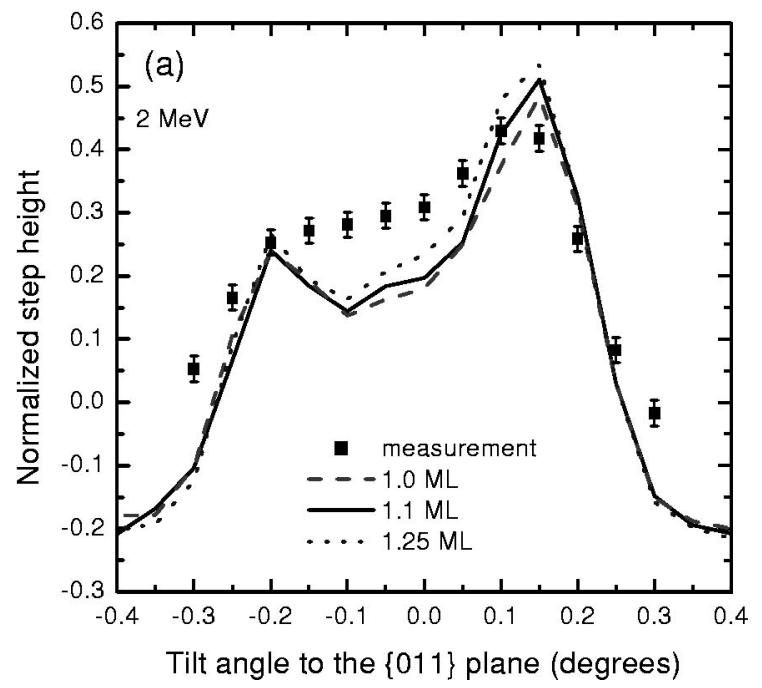

Thus, simulations of planar channeling on the InAs/GaAs sample reproduce the correct overall shape of the step height curves, but they are inadequate to obtain a detailed resemblance with the measurements. Furthermore, the outcome of a comparison of a number of simulations with the measurements is not unambiguous, and this implies that for this sample, the translation of the $\{011\}$ planes cannot be determined from planar channeling measurements and $\mathrm{MC}$ simulations.

\section{CONCLUSIONS}

Axial and planar channeling measurements and simulations are performed on a InAs/GaAs sample with ten coherent InAs nanofilms to determine the lattice deformation of the buried nanofilms.

The axial channeling measurements can be simulated adequately with the Monte Carlo simulation program FLUX7, and the translation of the GaAs $\{011\}$ lattice strings across

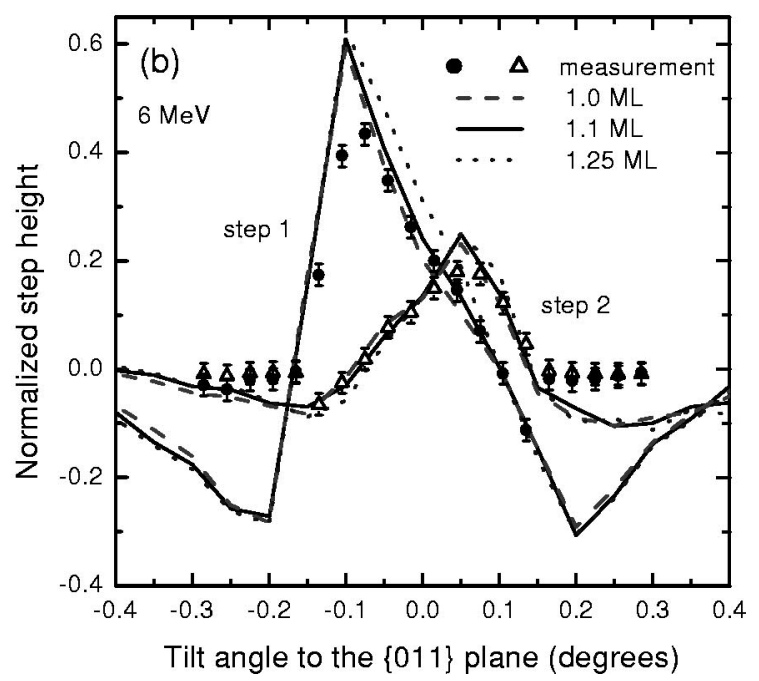

FIG. 7. Calculated $\{011\}$ planar step height curves for InAs layers with a thickness of 1.0, 1.1, and $1.25 \mathrm{ML}$ for 2 (a) and 6 (b) MeV He ions. The measured step height curves are also shown. 

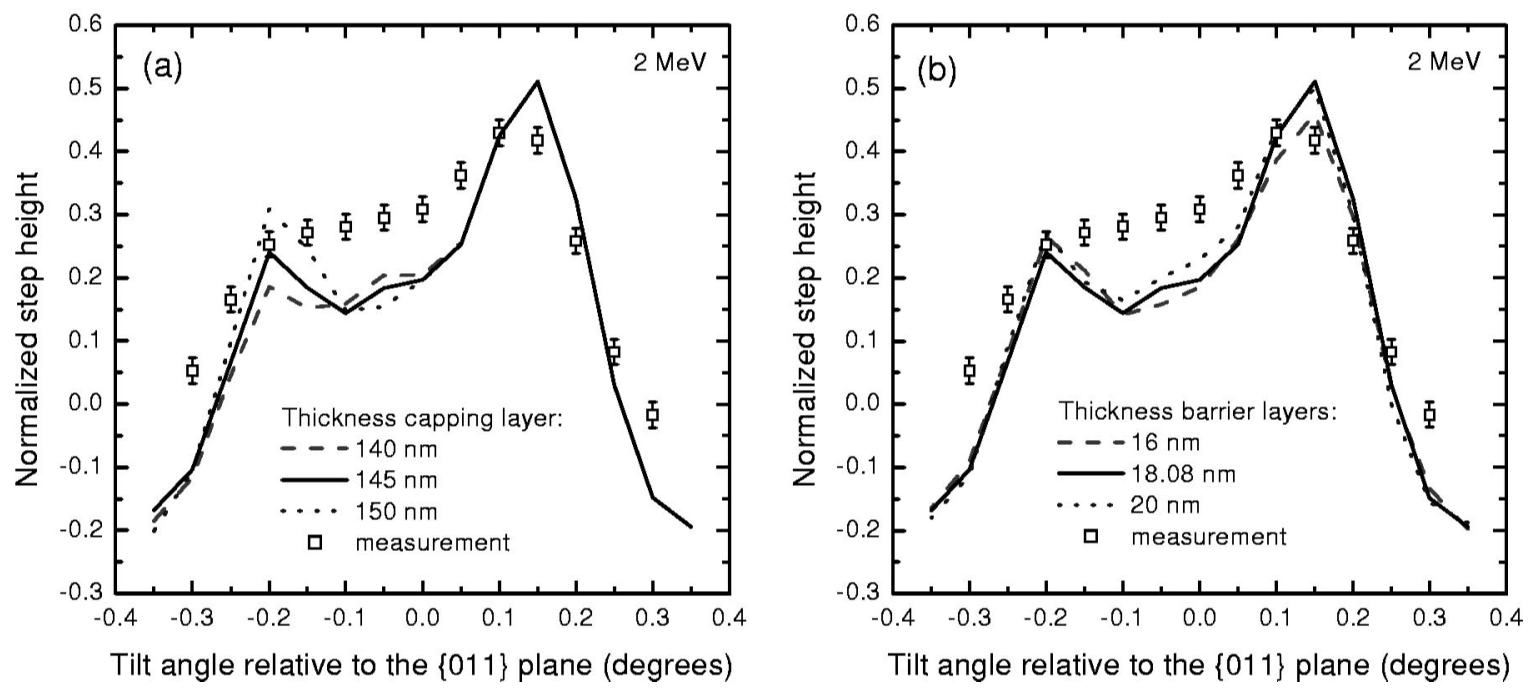

FIG. 8. Calculated $\{011\}$ planar step height curves with capping layers with a thickness of $140,144.9$, and $150 \mathrm{~nm}$ (a) and with barrier layers with a thickness of 16, 18.08, and $20 \mathrm{~nm}$ (b) for $2 \mathrm{MeV} \mathrm{He}^{+}$ions. The measured step height curve is also shown.

each InAs layer can be determined with an accuracy of 0.004 $\mathrm{nm}$. The contributions of the separate InAs layers to the step in a channeled RBS spectrum cannot be resolved, but the angular dependence of the height of this step is an average of the tetragonal distortion in the individual InAs layers.

Also planar channeling measurements are presented, which show two steps in the spectra for experiments with 6 $\mathrm{MeV} \mathrm{He}^{+}$ions. This behavior is caused by the specific combination of the thickness of the barrier layers in between the InAs nanofilms and the wavelength of the oscillating trajectories of the channeled ions. The general outcome of the measurements can be reproduced satisfactorily with the MC simulations, but a detailed agreement is not achieved. The calculated step height curves are insensitive to changes in the translation of the $\{011\}$ planes, which implies that for this sample the tetragonal distortion cannot be determined from planar channeling measurements, in contrast to the results for axial channeling measurements.

\section{ACKNOWLEDGMENTS}

The authors wish to thank Willem van der Vleuten and Paul Koenraad for providing the InAs/GaAs sample.
*Author to whom correspondence should be addressed. FAX: +31 4024380 60. Present address: Cyclotron Laboratory, Department of Applied Physics, Eindhoven University of Technology, P.O. Box 513, 5600 MB Eindhoven, The Netherlands. Electronic address: L.J.van.Ijzendoorn@tue.nl

${ }^{1}$ L.J.M. Selen, F.J.J. Janssen, L.J. van IJzendoorn, M.J.J. Theunissen, P.J.M. Smulders, and M.J.A. de Voigt, Nucl. Instrum. Methods Phys. Res. B 161-163, 492 (2000).

${ }^{2}$ L.J.M. Selen, Ph.D. thesis, Eindhoven University of Technology, 2001.

${ }^{3}$ L.J.M. Selen, F.J.J. Janssen, L.J. van IJzendoorn, and M.J.A. de Voigt, Nucl. Instrum. and Meth. B (to be published).

${ }^{4}$ S.T. Picraux, W.K. Chu, W.R. Allen, and J.A. Ellison, Nucl. In- strum. Methods Phys. Res. B 15, 306 (1986).

${ }^{5}$ S.T. Picraux, R.M. Biefeld, W.R. Allen, W.K. Chu, and J.A. Ellison, Phys. Rev. B 38, 11086 (1988).

${ }^{6}$ J. Brübach, A.Y. Silov, J.E.M. Haverkort, W.v.d. Vleuten, and J.H. Wolter, Phys. Rev. B 59, 10315 (1999).

${ }^{7}$ P.W.L. Van Dijk, Ph.D. thesis, Eindhoven University of Technology, 1997.

${ }^{8}$ P.J.M. Smulders and D.O. Boerma, Nucl. Instrum. Methods Phys. Res. B 29, 471 (1987).

${ }^{9}$ J.F. Ziegler, J.P. Biersack, and U. Littmark, The Stopping and Range of Ions in Solids (Pergamon Press, New York, 1985).

${ }^{10}$ L.C. Feldman, J.W. Mayer, and S.T. Picraux, Materials Analysis by Ion Channeling (Academic Press, New York, 1982), Chap. 3. 